\title{
Bcl2L12 with a BH3-like domain in regulating apoptosis and TMZ-induced autophagy: A prospective combination of ABT-737 and TMZ for treating glioma
}

\author{
MING-CHANG YANG ${ }^{2,3^{*}}$, JOON-KHIM LOH ${ }^{4,5^{*}}$, YI-YANG LI ${ }^{1,2}$, WEN-SHENG HUANG ${ }^{1}$, \\ CHIA-HUA CHOU ${ }^{1,2}$, JIIN-TSUEY CHENG ${ }^{2}$, YENG-TSENG WANG ${ }^{1}$, ANN-SHUNG LIEU ${ }^{5}$, \\ SHEN-LONG HOWNG ${ }^{5}$, YI-REN HONG ${ }^{1,2,4}$ and AN-KUO CHOU ${ }^{6}$

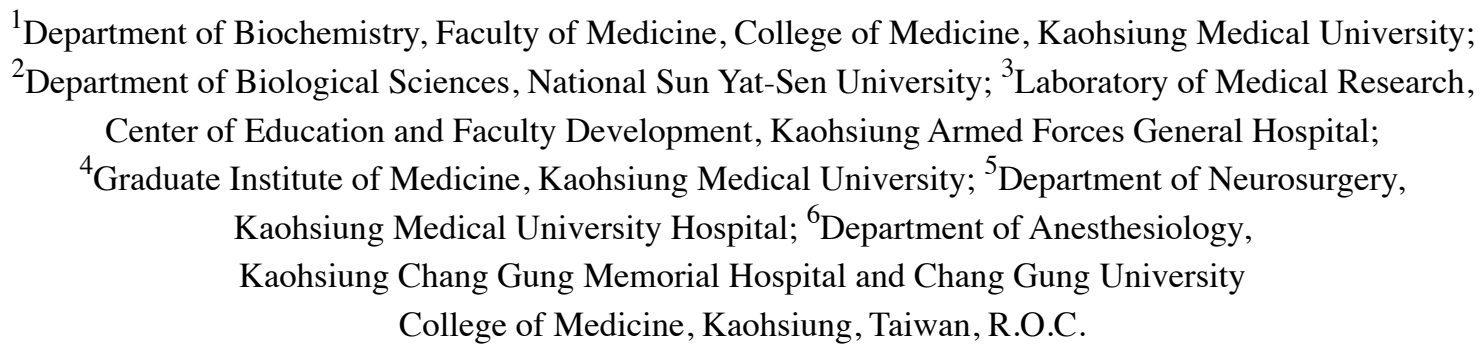

Received October 27, 2014; Accepted December 29, 2014

DOI: $10.3892 /$ ijo.2015.2838

\begin{abstract}
Bcl2L12 as a new member of the Bcl2 family, which contains a $\mathrm{BH} 2$ domain and shares a lower amino acid similarity with other $\mathrm{Bcl} 2$ family proteins. $\mathrm{Bcl} 2 \mathrm{~L} 12$ is reported to be involved in apoptosis regulation, but this role remains controversial in different cancer type. Temozolomide (TMZ) is currently used to intervene glioma multiforme (GBM), but an acquired chemotherapeutic resistance maybe occurred due to undesired autophagy. Previous studies uncovered that $\mathrm{Bcl} 2 \mathrm{~L} 12$ may interact with Bcl-xL and may harbor a $\mathrm{BH} 3-$ like domain. Therefore, we investigated whether this BH3-like domain is responsible for the Bcl2L12 anti-apoptotic prop-
\end{abstract}

Correspondence to: Professor Yi-Ren Hong, Department of Biochemistry, Faculty of Medicine, College of Medicine, Kaohsiung Medical University, Kaohsiung, Taiwan, R.O.C.

E-mail:m835016@cc.kmu.edu.tw

Dr An-Kuo Chou, Department of Anesthesiology, Kaohsiung Chang Gung Memorial Hospital and Chang Gung University College of Medicine, Kaohsiung, Taiwan, R.O.C.

E-mail: edmundchou@gmail.com

${ }^{*}$ Contributed equally

Abbreviations: GBM, glioblastoma; MOM, mitochondrial outer membrane; $\mathrm{BH}, \mathrm{Bcl} 2$ homology; TM, transmembrane; STS, staurosporine; TMZ, temolozomide; h, hydrophobic; Bcl2L12, Bcl2like-protein 12; PxxP, proline-rich region; $\mathrm{CRYAB}, \alpha \mathrm{B}$-crystallin

Key words: glioma multiforme, $\mathrm{Bcl} 2 \mathrm{~L} 12, \mathrm{Bcl} 2$ family proteins, apoptosis, BH3-like domain erty. Moreover, we tested whether ABT-737, a BH3 mimetic agent, can be combined with TMZ to treat GBM. We aligned Bcl2L12 with Bcl2 family members, compared interacting pattern of $\mathrm{BH} 3$ domain and their protein $3 \mathrm{D}$ structure. We identified that $\mathrm{Bcl} 2 \mathrm{~L} 12$ interacts with $\mathrm{Bcl}-\mathrm{xL}$ and $\mathrm{Bcl} 2$ in yeast two-hybrid system. Bcl2L12 $2_{192-220}$ was a minimal region for Bcl2L12-Bcl-xL interaction. Five-point mutations with respect to hydrophobic and charge residues were generated to test whether they are the key residue of $\mathrm{BH} 3$-like domain. Our data showed that both h1 (L213) and h2 residue (L217) are essential for Bcl2L12 interacting with Bcl2 family proteins. Ectopically expressed h1 or h2 mutant in U87MG cell line resulted in reactivation of cleaved-PARP, caspase-3 and cytochrome $c$ releasing compared to $\mathrm{Bcl} 2 \mathrm{~L} 12$ wt group. Implementing ABT-737 combined with TMZ provided a superior effect on apoptosis induction in Bcl2L12 wt group, which effectively reactivated apoptotic markers. Altogether, our findings indicated that $\mathrm{Bcl} 2 \mathrm{~L} 12$ retains a $\mathrm{BH} 3$-like domain, which is important for the Bcl2L12 anti-apoptotic property and TMZ-induced autophagy. Our results basically support the idea of using ABT-737 to counteract the anti-apoptotic role of Bcl2L12 and sensitize drug response of the GBM cells to TMZ.

\section{Introduction}

Glioblastoma (GBM) is a most aggressive glioma, and it is the most common brain tumor in adult and second most common in children. Survival rate remains poor although it has improved over the last five years $(1,2)$, is usually associated with a 2-year survival rate of only $10-25 \%$ (3). One major strategy to anticancer growth is to induce tumor apoptosis. Multiple apoptotic signals involved in the intrinsic pathway may result in alterations of permeability of the mitochondrial 
outer membrane (MOM) and cause the release of apoptogenic factors, including cytochrome $c$ (4). By following, cytochrome $c$ can promote formation of apoptosomes. Once the initiator caspase-9 is activated by apoptosome, effector caspase (caspase-3/7) will be activated to launch apoptosis. The signaling posterior to death receptor and ligand binding is further transducing and activates initiator caspase- 8 to trans-activate effector caspases (5). The intrinsic pathway is controlled by interactions of $\mathrm{Bcl} 2$ family members (6). According to the protein structure, the $\mathrm{Bcl} 2$ family members have at least one of the $\mathrm{Bcl} 2$ homology (BH) domains (7). Moreover, proteins in Bcl2 family can be divided into three functional groups based on their domain composition. One is the anti-apoptotic group, such as $\mathrm{Bcl} 2, \mathrm{Bcl}-\mathrm{xL}, \mathrm{Bcl}-\mathrm{W}$, Mcl-1 and A1, containing BH1-4 domains. These proteins can sequester pro-apoptotic protein or BH3-only activator to facilitate their anti-apoptosis function. The pro-apoptotic group, Bax and Bak, containing BH1-3 and transmembrane (TM) domain. These groups of proteins are essential effectors responsible for controlling permeability of MOM. The third group is the $\mathrm{BH} 3$-only group that proteins harbor only BH3 domain. The BH3-only proteins can be subdivided into activators (e.g., Bid and Bim) and sensitizers (e.g., Bad, Bik, Bmf, Hrk, Noxa and PUMA) (8).

Upon apoptosis, the BH3s activate Bax and Bak to mediate cytochrome $c$ efflux, leading to caspase activation (9-14). Conversely, the anti-apoptotic Bcl2, Bcl-xL, and Mcl-1 sequester Bax/Bak or activator BH3s into inert complexes, thus preventing Bax/Bak activation $(9,11,14,15)$. The remaining $\mathrm{BH} 3 \mathrm{~s}$ do not activate $\mathrm{Bax} / \mathrm{Bak}$ directly but instead prevent the anti-apoptotic Bcl2 members from sequestering the $\mathrm{Bax} / \mathrm{Bak}$ or the activator $\mathrm{BH} 3 \mathrm{~s}(11,14-18)$. A stepwise activation model of Bax and Bak is driven by activator BH3s. The $\alpha 1$ helix of Bax stabilizes and thereby controls the engagement of the $\alpha 9$ helix in the dimerization pocket. Activator BH3s bind transiently to the $\alpha 1$ helix of Bax to unleash auto-inhibition, which allows for the structural reorganization by exposing both $\mathrm{N}$ and $\mathrm{C}$ terminus. The $\mathrm{C}$-terminal transmembrane domain hence becomes available for insertion into the MOM. The activator $\mathrm{BH} 3 \mathrm{~s}$ remain associated with the $\mathrm{N}$-terminally exposed Bax to drive the homo-oligomerization of mitochondrial localized Bax. Bak, an integral mitochondrial membrane protein, constitutively exposes its $\alpha 1$ helix and requires activator $\mathrm{BH} 3 \mathrm{~s}$ to trigger its homo-oligomerization. The homo-oligomerization of Bax or Bak appears to involve the interaction between the $\mathrm{BH} 3$ domain of one molecule and the canonical dimerization pocket of the other monomer (19). Mutations in BH3 domain abolish their homo-oligomerization, and the same strategy is utilized for the heterodimerization between BH3s and antiapoptotic Bcl2 members $(20,21)$.

The Bcl2-like 12 (Bcl2L12) gene was discovered and cloned by Scorilas et al (22) in 2001, as a newly identified member of the Bcl2 family, containing a highly conserved $\mathrm{BH} 2$ domain, a BH3-like domain and a proline-rich region. Currently, two functional splicing variants of the Bcl2L12 gene are known: one consisting of seven coding exons and producing a 334-amino acid protein with a molecular mass of $36.8 \mathrm{kDa}$ and another one resulting from alternative splicing and giving rise to a protein of 176 amino acids, a splice variant called Bcl2L12A which lacks exon 3 (143 bp) (22). Expression of the full-length mRNA transcript has been observed in many tissues, including breast, thymus, prostate, fetal liver, colon, placenta, pancreas, small intestine, spinal cord, kidney and bone marrow, whereas the Bcl2L12A is mainly expressed in fetal liver, spinal cord and skeletal muscle (22). Previous studies showed that Bcl2L12 localized in both nucleus and the cytosol $(23,24)$. The biological role of Bcl2L12 is yet completely understood. Bcl2L12 exhibits pro-apoptotic activity in breast tumor and gastric cancer (25-27). A 3-fold increase of Bcl2L12 levels was demonstrated in non-cancerous compared to cancerous stomach tissues (27). In breast cancer, both proteins highly expressed in normal breast tissue, and it was documented that Bcl2L12 as a favorable prognosis marker and the knock down of its expression leads to a cisplatin-resistance of a breast cancer line MDA-MB231 (25). In nasopharyngeal cancer, Bcl2L12 expression status was also found to be positively associated with the presence of distant metastases. Moreover, Bcl2L12 expression is an unfavorable and independent prognostic indicator of short-term relapse in nasopharyngeal carcinoma, indicating that Bcl2L12 mRNA expression may constitute a novel biomarker for the prediction of short-term relapse in nasopharyngeal carcinoma (?). In contrast, both two Bcl2L12 are ubiquitously overexpressed in primary human GBMs and may be associated with the resistance to chemotherapeutic agent-induced apoptosis that is an important hallmark of this disease (24). Furthermore, it has been reported that Bcl2L12 is an inhibitor of post-mitochondrial effector caspase activation, as it binds to and inhibits caspase-7 and upregulates the caspase-3-specific inhibitor $\alpha \mathrm{B}$-crystallin (CRYAB). $\mathrm{Bcl} 2 \mathrm{~L} 12$ attenuates endogenous p53-directed transcriptomic changes after genotoxic stress and inhibits p53-dependent DNA damage-induced apoptosis (24).

Gliomas have been shown to exhibit disrupted intrinsic and extrinsic apoptosis signaling pathways, and the resultant inefficient caspase activation is thought to contribute to gliomagenesis and chemo-/radiotherapy resistance (28). Using TMZ, it was reported that ROS-dependent autophagy induction may abrogate its effectiveness in triggering apoptosis in glioma (29). On the other hand, GBM overexpressed with Bcl2L12 also creates an unfavorable environment to be intervened by DNA damaging agents. In this study, we explored whether Bcl2L12 orchestrates its anti-apoptosis function through its interacting with $\mathrm{Bcl} 2$ family members by the BH3-like domain. Besides, ABT-737, a BH3 mimetic agent, was tested for its possible combination with TMZ to provide a better outcome of glioma treatment.

\section{Materials and methods}

Cloning. For vector construction of Bcl2L12, Bcl-xL, Bcl2, Bax into pACT2/pAS2-1 for yeast two-hybrid assay or pEGFP-C1 for overexpression, PCR was used to generate DNA fragments containing desired genes using the primer containing XhoI and BamHI restriction enzyme recognition site. For gene-specific PCR, $100 \mathrm{ng}$ genomic DNA was used as template, $2.5 \mu 1,10 \mathrm{X}$ reaction buffer (Takara Bio Inc., Shiga, Japan), $4 \mu 1,2.5 \mathrm{mM}$ dNTPs (Takara Bio Inc.), $0.2 \mu \mathrm{l}$ DNA polymerase (5 U/ $\mu \mathrm{l}$ ) (Takara Bio Inc.), $1 \mu \mathrm{l}$ of $10 \mu \mathrm{M}$ 
primers were added into a $25-\mu 1$ reaction mix. The PCR conditions were denaturation at $95^{\circ} \mathrm{C}, 30 \mathrm{sec}$; followed by $30 \mathrm{sec}$ annealing, extension at $72^{\circ} \mathrm{C}$ for 35 cycles on GeneAmp 9700 PCR System (Applied Biosystems, Foster City, CA, USA). The PCR products were separated on $2.0 \%$ agarose gel and visualized by staining with $0.5 \mu \mathrm{g} / \mathrm{ml}$ ethidium bromide. The PCR products with correct sizes were further purified using PCR clean-up kit (GeneMark Technology Co., Ltd., Tainan, Taiwan) and subjected to restriction enzyme digestion. Plasmid DNA was also double-strand sequenced to confirm its correctness (Mission Biotech, Taipei, Taiwan).

Yeast two-hybrid assay. Yeast (YRG2) was inoculated into $5 \mathrm{ml} \mathrm{YPD}$ medium and grown at $28^{\circ} \mathrm{C}, 240 \mathrm{rpm}$ for $20 \mathrm{~h}$. YPD medium $(45 \mathrm{ml})$ was added into original yeast culture to refresh its growth and further incubated for $4 \mathrm{~h}$. To detect whether gene A interacts with gene B, the pACT2 vector/ gene A $(1.2 \mu \mathrm{g})$ was pre-mixed with pAS2-1 vector/gene B $(1.2 \mu \mathrm{g})$ then further added with $10 \mu \mathrm{l}$ boiled salmon sperm and $800 \mu \mathrm{l}$ of aforementioned yeast solution. Thereafter, the reaction was vortex completely and incubated at $28^{\circ} \mathrm{C}, 240 \mathrm{rpm}$ for $30 \mathrm{~min}$, then added with $80 \mu \mathrm{l}$ DMSO (Sigma-Aldrich Corp., St. Louis, MO, USA), the reaction was heat-shocked at $42^{\circ} \mathrm{C}$ for $15 \mathrm{~min}$ then placed on ice for $2-5 \mathrm{~min}$. The reaction was centrifuged at 3,000 rpm, for $3 \mathrm{~min}$ and the supernatant was discarded. Sterilized water $(200 \mu 1)$ was used to re-suspend the transformed yeast pellet, then $100 \mu \mathrm{l}$ of the reaction mixture was spread on nutritional deficiency plates $\mathrm{G} 2$ and G3, respectively. The G2 or G3 plates were incubated at $28^{\circ} \mathrm{C}$ for colony growing. Sterilized filter papers were used to cover the G2/G3 plates. The filter papers attached the yeast colonies and were further dipped into liquid nitrogen for $40 \mathrm{sec}$ to break cell walls of the attached yeast. A $1,600 \mu \mathrm{l}$ of $\mathrm{X}$-gal solution was added onto another filter and incubated at $28^{\circ} \mathrm{C}$ for detecting whether bait protein would interact with prey protein.

Site-directed mutagenesis. The specific primers containing desired mutations [h1, h2, h3, charge and h4, partly as designated as previous report (30)] and the complementary sequences surrounding to mutation sites were designed and synthesized. After PCR amplification, $1.5 \mu 1$ DpnI (10 U/ $\mu \mathrm{l})$ was added for digestion at $37^{\circ} \mathrm{C}$ for $10 \mathrm{~min}$. DpnI treated DNA $(2 \mu \mathrm{l})$ was transferred into $45 \mu \mathrm{l}$ of prepared competent cells. After incubation on ice for $30 \mathrm{~min}$, heat shock was carried out at $42^{\circ} \mathrm{C}$ water bath for $30 \mathrm{sec}$. Then the reaction mixture was left on ice for $2 \mathrm{~min}$. Then $500 \mu \mathrm{l} \mathrm{LB}$ medium was added and incubated at $37^{\circ} \mathrm{C}, 200 \mathrm{rpm}$ for $1 \mathrm{~h}$. After incubation, bacterial cultures were spread on selective plates containing antibiotics and incubated at $37^{\circ} \mathrm{C}$ for $16-18 \mathrm{~h}$. Several colonies were picked up for plasmid preparation, restriction enzyme digestion and sequencing to confirm the desired mutations.

Protein structure prediction. I-TASSER server is a web-based program for protein structural and functional predictions. It allows users to automatically generate predictions of 3D structure and biological function of protein molecules from their amino acid sequences. When an amino acid sequence is submitted, the server tries to retrieve template proteins of similar folds (or super-secondary structures) from the PDB library by LOMETS, a locally installed metathreading approach (31). Therefore, we combined the amino acid sequences with $\mathrm{Bcl} 2 \mathrm{~L} 12, \mathrm{Bcl} 2, \mathrm{Bcl}-\mathrm{xL}$ and $\mathrm{Bax}$, to obtain protein secondary and $3 \mathrm{D}$ structure for cross-sectional comparisons.

Cell culture, transfection and treatments. Human glioblastoma U87MG (HTB-14) and T98G (CRL-1690) cell lines were purchased from American Type Culture Collection (ATCC). Cells were cultured using $\alpha$-MEM and MEM supplemented with $10 \%$ FBS and penicillin with streptomycin $(100 \mathrm{IU} / \mathrm{l})$ at $37^{\circ} \mathrm{C}, 5 \% \mathrm{CO}_{2}$ in air atmosphere. For transient transfections, cells were seeded into $100-\mathrm{mm}$ diameter culture dishes (Becton-Dickinson, San Jose, CA, USA) at a density of $1 \times 10^{7}$ cells per dish. DNA was transfected into cells using Lipofectamine 2000 transfection reagent (Invitrogen, Carlsbad, CA, USA). For apoptosis induction, STS (SigmaAldrich Corp.) and TMZ were used. After transfection for 12-16 h, $0.5 \mu \mathrm{M} \mathrm{STS}$ and $400 \mu \mathrm{M}$ TMZ were added into culture dish and incubated for another $24 \mathrm{~h}$ (STS) or $48 \mathrm{~h}$ (TMZ) to trigger apoptosis (STS was the positive control of apoptosis induction).

Quantitative PCR. cDNA was synthesized from total RNA for each of the studied groups using an Impron II reverse transcriptase kit (Promega Corp., Madison, WI, USA). All primer pairs with respect to Bcl2L12, LC3B, Beclin-1 and GAPDH were designed using a web-based program provided by GeneScript.com. All were qualified and demonstrated: i) high amplification efficiency (>96\%) across a wide range of cDNA dilutions; ii) specific single products in dissociation curve analysis; and iii) melting temperatures similar to those predicted by oligonucleotide software. Quantitative PCR was performed with Power SYBR Green dye and an ABI StepOne Plus Real-Time PCR system (Applied Biosystems). The difference in the cycle threshold (dCT) for target gene (LC3B, Beclin-1 and Bcl2L12) mRNA expression was calculated by subtracting the geometric mean of the cycle threshold for the reference gene (GAPDH) from the cycle threshold of the target gene mRNA. Because this $\mathrm{dCT}$ represents the $\log ^{2}$-transformed expression ratio of the target transcript to the geometric mean of the reference gene, the relative expression level of the target gene mRNA was determined as 2-dCT. The relative target gene expression of the studied groups is shown as a fold increasing pattern with standard deviations.

Western blotting. Lysis buffer was used to prepare the total lysates from cultured cells. For detecting cytochrome $c$ efflux, the cytosolic fraction was prepared by Mitochondria/Cytosol Fractionation kit (Merck Millipore, Billerica, MA, USA) according to the manufacturer's protocol. Protein concentration was determined using Protein Assay reagent (Bio-Rad, Hercules, CA, USA). Protein lysates were separated on $12 \%$ SDS-PAGE and then transferred onto methanol-treated PVDF membrane. The transferred membranes were blocked by $5 \%(\mathrm{w} / \mathrm{v})$ non-fat dry milk in TBST with gentle shaking for $1 \mathrm{~h}$. Then the membrane was incubated with primary antibodies: anti-LC3B, anti-Atg5, anti-Beclin-1, anti-full 
Table I. The results of yeast two hybrid system to detect the minimal region responsible for interaction with $\mathrm{BclxL}, \mathrm{Bcl} 2$ and Bax.

Protein interaction with indicated construct in BD vector pAS2-1

Bcl2L12 fragments $\mathrm{BclxL}_{1-209} \quad \mathrm{Bcl}_{1-211} \quad \mathrm{Bax}_{1-171} \quad \mathrm{pAS} 2-1$ in $\mathrm{AD}$ vector $\mathrm{pACT} 2$

\begin{tabular}{lcccc}
\hline $\mathrm{Bcl} 2 \mathrm{~L} 12_{70-334}$ & $\mathrm{~B}^{+}$ & $\mathrm{B}^{+}$ & $\mathrm{B}^{+}$ & - \\
$\mathrm{Bcl} 2 \mathrm{~L} 12_{70-266}$ & $\mathrm{~B}^{+}$ & $\mathrm{B}^{+}$ & $\mathrm{B}^{+}$ & - \\
$\mathrm{Bcl} 2 \mathrm{~L} 12_{70-240}$ & $\mathrm{~B}^{+}$ & $\mathrm{B}^{+}$ & $\mathrm{B}^{+}$ & - \\
$\mathrm{Bcl} 2 \mathrm{~L} 12_{90-229}$ & $\mathrm{~B}^{+}$ & $\mathrm{B}^{+}$ & $\mathrm{B}^{+}$ & - \\
$\mathrm{Bcl} 2 \mathrm{~L} 12_{90-220}$ & $\mathrm{~B}^{+}$ & $\mathrm{B}^{+}$ & $\mathrm{B}^{+}$ & - \\
$\mathrm{Bcl} 2 \mathrm{~L} 12_{70-117}$ & - & - & - & - \\
$\mathrm{Bcl} 2 \mathrm{~L} 12_{70-152}$ & - & - & - & - \\
$\mathrm{Bcl} 2 \mathrm{~L} 12_{70-191}$ & - & - & - & - \\
$\mathrm{Bcl} 2 \mathrm{~L} 12_{192-240}$ & $\mathrm{~B}^{+}$ & $\mathrm{B}^{+}$ & $\mathrm{B}^{+}$ & - \\
$\mathrm{pACT} 2$ & - & - & - & - \\
\hline
\end{tabular}

The full-length of Bcl2L12 is unable to bind with Bcl-xL, Bcl2 and Bax. $\mathrm{B}^{+}$, interaction; -, no interaction. length PARP, anti-PARP (cleaved form), anti-caspase-9/-3 (cleaved form), anti-cytochrome $c$, anti-Bax and anti-Bcl-xL (Cell Signaling Technology, Beverly, MA, USA), anti-GFP, and anti- $\beta$-actin (Santa Cruz Biotechnology, Santa Cruz, CA, USA). The primary antibodies were used in $1 \%$ non-fat dry milk or 5\% BSA dilute with TBST. The PVDF membranes were washed 5 times in TBST, 5 min each. Then secondary antibodies conjugated with horseradish peroxidase were added in $1 \%$ non-fat dry milk and incubated at room temperature for another $1 \mathrm{~h}$, followed by 5 washes with TBST. The protein signaling was developed using ECL reagent (GE Healthcare, Piscataway, NJ, USA). The chemiluminescence signal was recorded on X-ray film (Fuji, Tokyo, Japan) and imaging using developer and fixer agents (Kodak, Rochester, NY, USA).

Statistical analysis. Data are expressed as mean \pm standard deviation. Statistical significance between the groups was examined by either Student's t-test or Wilcoxon's Rank-Sum test. P-values $<0.05$ were considered as a statistically significant difference.
$\mathbf{A}$

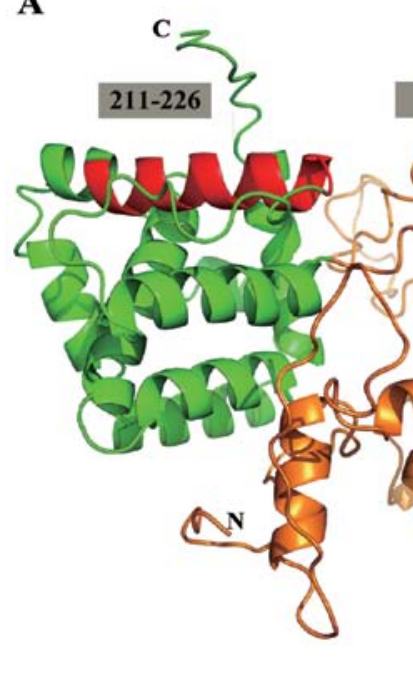

C

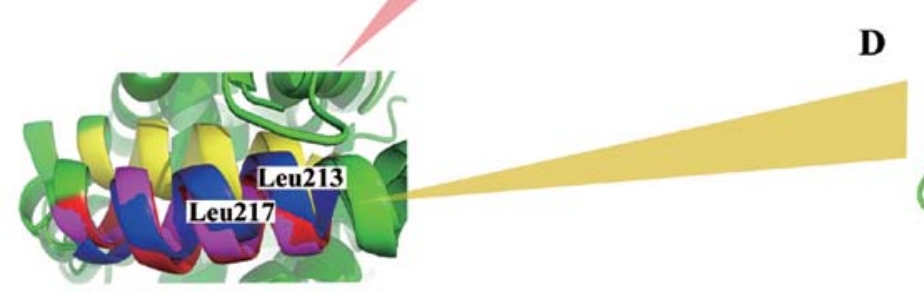

B

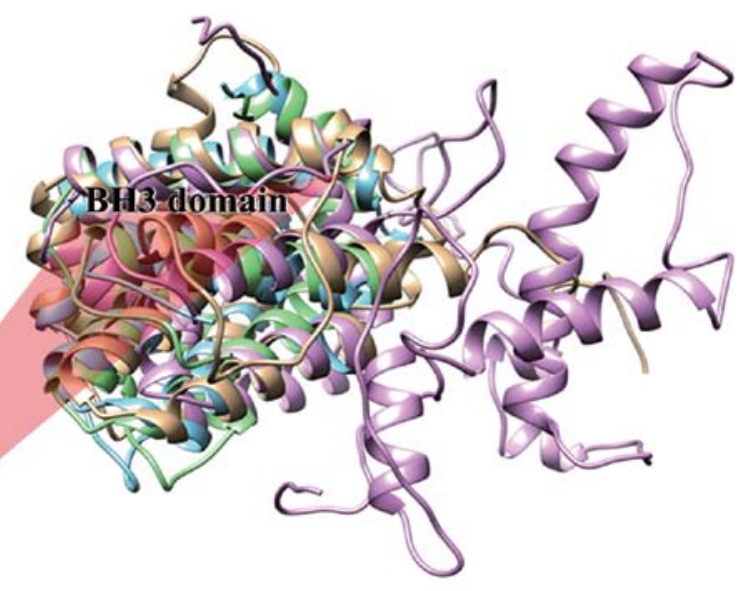

D

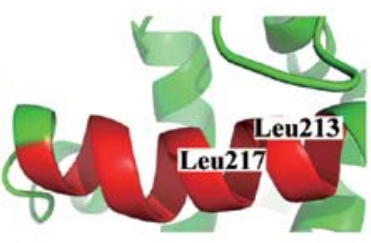

Figure 1. The structural simulation of Bc12L12 and comparison of BH3 Domain of studied Bc12 family proteins. (A) The predicted protein 3D structure of Bcl2L12. The N-terminal protein of Bcl2L12 (homology modeling, 1-173 amino residues) (orange), harboring a unique folding pattern with extra coiled-coiled domain compared to others Bcl2 family proteins; in addition, this region was suspected to be involved in Bcl2L12 biofunction. The BH3 domain of Bcl2L12 (BH3 domain, 211-226th amino residues) (red). The region spanning from residues 174 to 334 (green). N, N-terminus, C, C-terminus. (B) The whole protein structure of studied Bcl2 family proteins were homologically overlapped, it was observed that Bcl2L12 only restrictedly overlapped with $\mathrm{Bcl} 2, \mathrm{Bcl}-\mathrm{xL}$ and $\mathrm{Bax}$ in its $\mathrm{C}$-terminal region. (C) The structure simulation of four Bcl2 family proteins using the amino acid residues corresponding to $\alpha 2$ or $\alpha 9$ helix. The core residues of BH3 domain of BAX [PDB ID, 1F16, 54-71 amino residues (37)] (blue), the BH3 domain of Bcl-xL [PDB ID, 1R2D, 90-98 amino residues (44)] (colored in magentas), the BH3 domain of Bcl2 [PDB ID, 2XA0, 93-108 amino residues (36)] (yellow) and the BH3 domain of Bcl2L12 [homology modeling, 211-226 amino residues as BH3-like motif as previously described (6)] (red). (D) The closed view of Bcl2L12 BH3-like domain revealed that it is comprised of approximately seven turns $\alpha$-helix structure (red). 
Table II. Comparing the domain structure of $\mathrm{Bcl} 2$ family proteins in this study.

\begin{tabular}{|c|c|c|c|c|c|c|c|c|}
\hline \multicolumn{4}{|c|}{ Anti-apoptotic } & \multirow{2}{*}{\multicolumn{2}{|c|}{$\frac{\text { Pro-apoptotic }}{\text { Bax }}$}} & & & \\
\hline & & Bcl-xL & Bcl2 & & & \multicolumn{3}{|c|}{ Bcl2L12 } \\
\hline \multicolumn{2}{|c|}{ BH-domain } & $\begin{array}{l}\text { Location of } \\
\alpha \text {-helix (a.a.) }\end{array}$ & & BH-domain & $\begin{array}{l}\text { Location of } \\
\alpha \text {-helix (a.a.) }\end{array}$ & BH-domain & & $\begin{array}{l}\text { Location of } \\
\alpha \text {-helix (a.a.) }\end{array}$ \\
\hline & & & & & & & $\alpha 1$ & $12-15$ \\
\hline & & & & & & & $\alpha 2$ & $20-31$ \\
\hline & & & & & & & $\alpha 3$ & $37-41$ \\
\hline & & & & & & & $\alpha 4$ & $84-91$ \\
\hline & & & & & & & $\alpha 5$ & $95-110$ \\
\hline & & & & & & & $\alpha 6$ & $127-146$ \\
\hline & & & & & & & $\alpha 7$ & $160-163$ \\
\hline$\alpha 1$ & $\mathrm{BH} 4$ & $4-19$ & $11-26$ & & $22-37$ & $\begin{array}{l}\text { BH4-like } \\
\text { domain? }\end{array}$ & $\alpha 8$ & $175-190$ \\
\hline$\alpha 2$ & BH3 & 84-99 & $91-106$ & BH3 & $57-72$ & BH3-like & $\alpha 9$ & $211-226$ \\
\hline$\alpha 3$ & & $104-112$ & $111-119$ & & $77-85$ & & $\alpha 10$ & $22-235$ \\
\hline$\alpha 4$ & BH1 & $120-132$ & $127-139$ & BH1 & $89-101$ & $\begin{array}{l}\text { BH1-like } \\
\text { domain? }\end{array}$ & $\alpha 11$ & $243-255$ \\
\hline$\alpha 5$ & & $137-156$ & $144-163$ & & $107-126$ & & $\alpha 12$ & $260-279$ \\
\hline$\alpha 6$ & & $162-176$ & $169-183$ & & $132-146$ & & $\alpha 13$ & $285-299$ \\
\hline$\alpha 7$ & $\mathrm{BH} 2$ & $180-183$ & $187-190$ & BH2 & $150-153$ & $\mathrm{BH} 2$ & $\alpha 14$ & $303-306$ \\
\hline$\alpha 8$ & & $188-195$ & $195-202$ & & $158-165$ & & $\alpha 15$ & $311-322$ \\
\hline TM & & $213-231$ & 219-237 & & 169-188 & & $\alpha 16$ & $326-328$ \\
\hline
\end{tabular}

\section{Results}

Bcl2L12 can interact with Bcl-xL and Bcl2; in addition, Bcl2L12 ${ }_{192-220}$ may be important to its interaction with Bcl- $x \mathrm{~L}$. According to results from yeast two-hybrid system shown in Table I, we revealed that Bcl2L12 ${ }_{70-334}$ can interact with Bcl-xL and $\mathrm{Bcl} 2$. To narrow down the region responsible for these interactions on $\mathrm{Bcl} 2 \mathrm{~L} 12$, different truncated $\mathrm{Bcl} 2 \mathrm{~L} 12$ fragments were generated to determine whether they can interact with either Bcl-xL or Bcl2 or both. As shown in Table I, Bcl2L12 ${ }_{192-240}$ interacts with Bcl-xL, but not Bcl2L12 ${ }_{70-191}$. $\mathrm{Bcl} 2 \mathrm{~L} 12_{90-220}$ also interacts with $\mathrm{Bcl}-\mathrm{xL}$; therefore, it is assumed that $\mathrm{Bcl} 2 \mathrm{~L} 12_{220-240}$ may be not critical for its interaction with Bcl-xL. Shorter Bcl2L12 truncated fragment (e.g., Bcl2L12 ${ }_{192-240}$ ) showed weaker interaction compared to that of the long Bcl2L12 truncated fragments (e.g., Bcl2L12 ${ }_{70-334}$ ). Altogether, it was revealed that $\mathrm{Bcl} 2 \mathrm{~L} 12_{192-220}$ as a minimal region may play an important role involved in the interaction between Bcl2L12 and Bcl-xL.

Bcl2L12 $211-226$ may contain a BH3-like domain, which is response for the interactions with $\mathrm{Bcl}-x \mathrm{~L}$ and $\mathrm{Bcl}$. Using a web-based program identifying protein-protein interaction sites (ISIS) (32), we preferentially predicted the possible crucial residues within the $\mathrm{Bcl} 2 \mathrm{~L} 12_{192-220}$ that are responsible for protein-protein interactions. In addition, we predicted the protein 3D structure of Bcl2L12 (Fig. 1A). The residue of 1-173 contains seven $\alpha$-helixes, whereas residue of 174-334 contains nine $\alpha$-helixes. The predicted BH3-like domain corresponded to residue of 211-226. Moreover, we homologically overlapped the whole protein structure of the studied Bcl2 family proteins (Fig. 1B), it was observed that Bcl2L12 was only restrictedly overlapped with $\mathrm{Bcl} 2, \mathrm{Bcl}-\mathrm{xL}$ and Bax in its C-terminal region. Hence, we further magnified the overlapped region of $\mathrm{BH} 3$ domain of these four proteins (Fig. 1C). As a result, BH3-like domain of Bcl2L12 can homologically be overlapped with Bcl-xL and Bax, but not $\mathrm{Bcl} 2$. The closed view of Bcl2L12 BH3-like domain revealed that it comprised of an approximately seven-turn $\alpha$-helix structure (Fig. 1D). Based on multiple sequence alignment and the protein structural simulations, we conclude the region corresponding to $\alpha 9$ helix of Bcl2L12 may be important and highly similar to the hydrophobic region ( $\alpha 2$ helix, BH3 domain) of the other Bcl 2 family proteins (Table II). Further, we narrowed the region down to $\mathrm{Bcl} 2 \mathrm{~L} 12_{211-226}$ as $\mathrm{BH} 3$-like domain (20) of Bcl2L12 and LXXXAE as core motif other than canonical LXXXXD (33). We suspected this region may be important and/or mediate the interactions with respect to Bcl-xL and Bcl2 as shown in Fig. 2.

For delineating whether Bcl2L12 BH3-like domain serves its function similarly to $\mathrm{Bax} \mathrm{BH} 3$ domain, we performed site-directed mutagenesis on several residues within the helix interacting surface (h1, h2, h3 and h4) (34) and we firstly predicted interacting residue (20) corresponding to Bax BH3 domain since mutations on these residues in Bax have been reported to reduce Bax-Bcl-xL interaction. We compared the interacting patterns of Bcl2L12 wild-type (wt) and mutants with respect to $\mathrm{Bcl}-\mathrm{xL}$ and $\mathrm{Bcl} 2$; in addition, 
A

Anti-apoptotic BCL-2 proteins

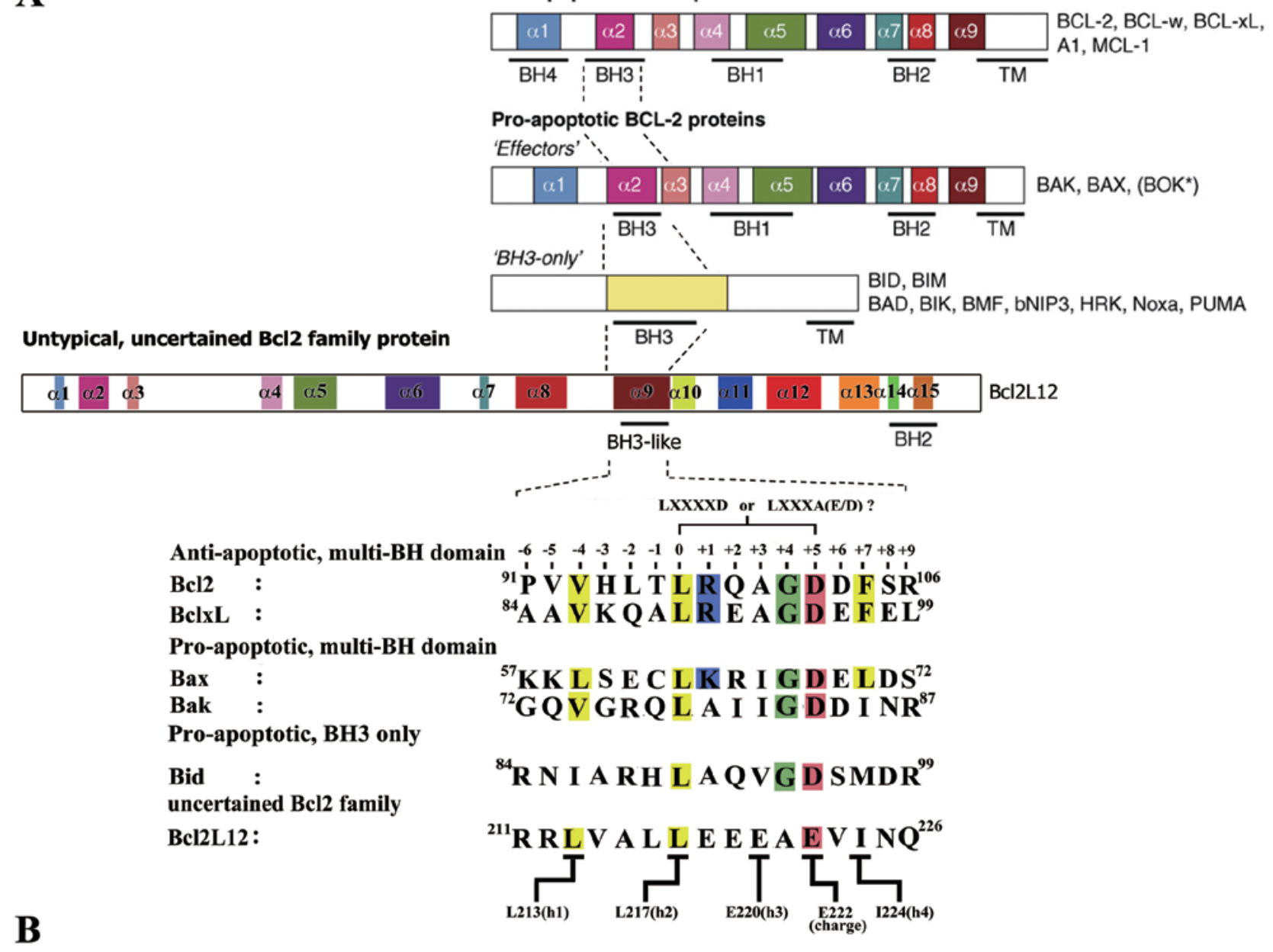

\begin{tabular}{|c|c|c|c|}
\hline \multirow{2}{*}{\multicolumn{2}{|c|}{$\begin{array}{l}\text { Bcl2L12/Bax wt or } \\
\text { mutant constructs in } \\
\text { AD vector - pACT2 }\end{array}$}} & \multicolumn{2}{|c|}{$\begin{array}{l}\text { Protein interaction with indicated } \\
\text { construct in BD vector - pAS2-1 }\end{array}$} \\
\hline & & BclxL $_{1-209}$ & Bcl2 1-211 $_{11}$ \\
\hline \multirow{6}{*}{ Bcl2L1270-266 } & wt & $\mathbf{B}^{+}$ & $\mathbf{B}^{+}$ \\
\hline & L213A h1 & - & - \\
\hline & L217A h2 & - & - \\
\hline & E220A h3 & $\mathbf{B}^{+}$ & $\mathbf{B}^{+}$ \\
\hline & E222A charge & $\mathbf{B}^{+}$ & $\mathbf{B}^{+}$ \\
\hline & I224A h4 & - & - \\
\hline
\end{tabular}

Figure 2. Sequence of Bcl2L12 BH3-like domain was aligned with BH3 domain of Bcl2 family proteins and the interacting patterns between Bcl2L12 wt and Bcl2L12 mutants were compared using yeast two-hybrid system. (A) Bcl2L12 harbors BH2 and BH3-like domain, and the domain composition is different from other members in Bcl2 family. However, the amino acid sequence of BH3-like domain shares a certain level of similarity to BH3 domain of different Bcl2 family proteins. The core motif of LXXXAE is similar to LXXXXD. The chosen residues for performing site-directed mutagenesis were indicated as I213 (h1), L217 (h2), L220 (h3), E222 (charge) and E224 (h4). Of note, pro-apoptotic Bcl2 members usually sequestered by anti-apoptotic members through the interactions of their BH3 domain with hydrophobic groove of anti-apoptotic Bcl2 family proteins. (B) Bcl2L12 $70-266$ was used to perform site-directed mutagenesis at the above sites, which correspond to h1, h2, h3, charge and h4 in the BH3-like domain to determine whether, and which site, is crucial for Bcl2L12 interacting with Bcl-xL and Bcl2 using the yeast two hybrid system. $\mathrm{B}^{+}$, positive interaction; -, no interaction.

the interacting pattern of $\mathrm{Bax} \mathrm{BH} 3$ mutant was investigated and compared. As expected, the interacting patterns between Bax BH3 domain and Bcl2L12 BH3-like domain did show high similarity (Table III), but Bcl2L12 may have different binding manner between $\mathrm{Bcl}-\mathrm{xL}$ and $\mathrm{Bcl} 2$, indicating that BH3 domain may not be equally responsible for Bcl2L12$\mathrm{BclxL}$ and Bax-Bcl-xL interaction (Table III, BclxL $\mathrm{L}_{1-209}$ L90A in lines 1 and 3 compare to $\mathrm{Bcl}_{1-211} \mathrm{~L} 97 \mathrm{~A}$ in lines 1 and 3). Moreover, it was revealed that $\mathrm{h} 2$ residue in $\mathrm{BH} 3$-like domain is important for Bc2L12 $2_{70-266}$ interacting with $\mathrm{Bcl}-\mathrm{xL}_{1-}$. 209 and possibly with $\mathrm{Bcl}_{21-211}$. Besides, the $\mathrm{h} 2$ residue is also crucial for $\mathrm{Bax}_{1-171}$ interacting with $\mathrm{Bcl}_{21-211}$. It is of note that when expressed these proteins, in yeast colonies took 3-5 days to grow to an appropriate size for filter assay. The colonies also showed a high variety in growth speed and we presumed this phenomenon may due to, in part, either to weaker interactions 


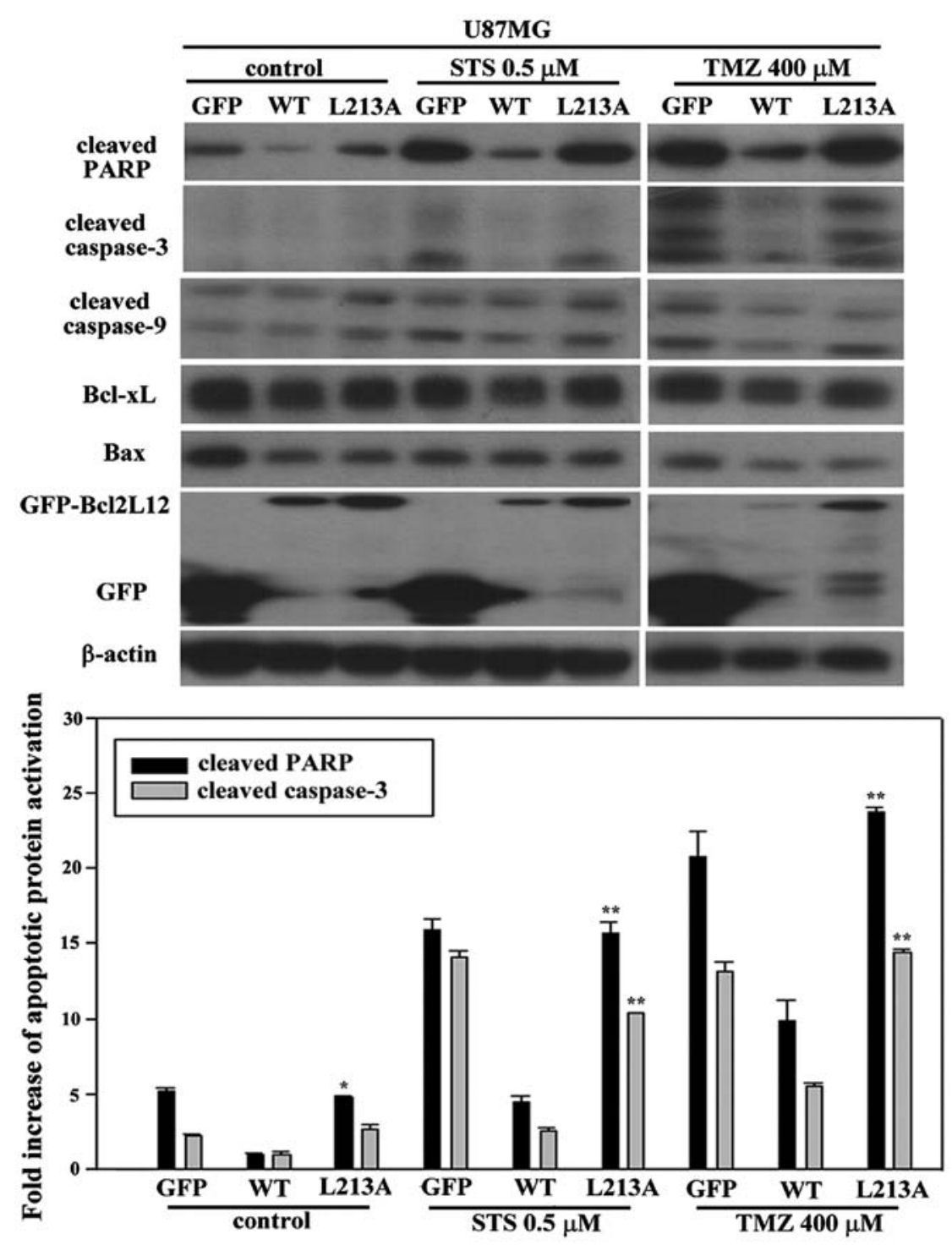

Figure 3. The BH3-like domain of Bc12L12 is involved in regulating apoptosis. Overexpressed Bc12L12 wt and its h1 mutant in U87MG cell line lead to different expression of apoptotic markers under different treatments (STS and TMZ). Overexpressed L213A mutant resulted in reactivation of apoptotic markers, including cleaved-PARP and cleaved caspase-3. The lower panel is the bar chart indicating that expression levels with respect to cleaved-PARP and cleaved caspase-3 of each group. The reference values are corresponding expression levels detected in the Bcl2L12 wt/control group.

Table III. Yeast two hybrid system detection of the critical residue affecting Bcl2L12 and/or Bax interaction with BclxL and $\mathrm{Bcl} 2$.

\begin{tabular}{|c|c|c|c|c|}
\hline & BclxL $_{1-209}$ & $\begin{array}{c}\text { BclxL }_{1-209} \\
\text { L90A }\end{array}$ & $\mathrm{Bcl}_{21-211}$ & $\begin{array}{c}\mathrm{Bcl}_{21-211} \\
\mathrm{~L} 97 \mathrm{~A}\end{array}$ \\
\hline Bcl2L12 ${ }_{70-266}$ & $\mathrm{~B}^{+}$ & $\mathrm{B}^{+}$ & $\mathrm{B}^{+}$ & - \\
\hline Bcl2L12 ${ }_{70-266} \mathrm{~L} 213 \mathrm{~A}$ & - & - & - & - \\
\hline $\operatorname{Bax}_{1-171}$ & $\mathrm{~B}^{+}$ & $\mathrm{B}^{+}$ & $\mathrm{B}^{+}$ & - \\
\hline $\mathrm{Bax}_{1-171} \mathrm{~L} 63 \mathrm{~A}$ & - & - & - & - \\
\hline
\end{tabular}

$\mathrm{B}^{+}$, interaction; -, no interaction.

of tested proteins or a negative side effect of yeast growth. The 3D structure simulation showed that structure computerized using sequences from Bcl2L12 BH3-like to $\mathrm{BH} 2$ domain was similar to that of Bcl-xL, Bcl2 and Bax (35-37), indicating that BH3-like domain may have the same function as BH3 domain of Bcl2 family proteins, especially Bax.

Bcl2L12 L213A and L217A mutant can abolish its anti-apoptosis role and cause re-activations of apoptotic markers in GBM cell line. U87MG cell line with expression of GFP alone, GFP-Bcl2L12 wt and GFP-Bcl2L12 L213A (h1 mutant), were treated with either STS $(0.5 \mu \mathrm{M})$ or TMZ $(400 \mu \mathrm{M})$ for 24 and $48 \mathrm{~h}$, respectively, to induce apoptosis. Regardless of the treatment drug, Bcl2L12 wt showed a lower activation of cleaved-PARP than other groups. When overexpressed Bc12L12 L213A, apoptotic markers were significantly reactivated during treatment with either STS or TMZ (Fig. 3). This result is consistent with the reported anti-apoptotic role of Bcl2L12 in GBM. Additionally, mutation on one of the residues (L213) of core motif did abolish anti-apoptotic role of Bcl2L12, which caused a significant elevation of apoptotic markers including cleaved-PARP and capase-3 in U87MG 


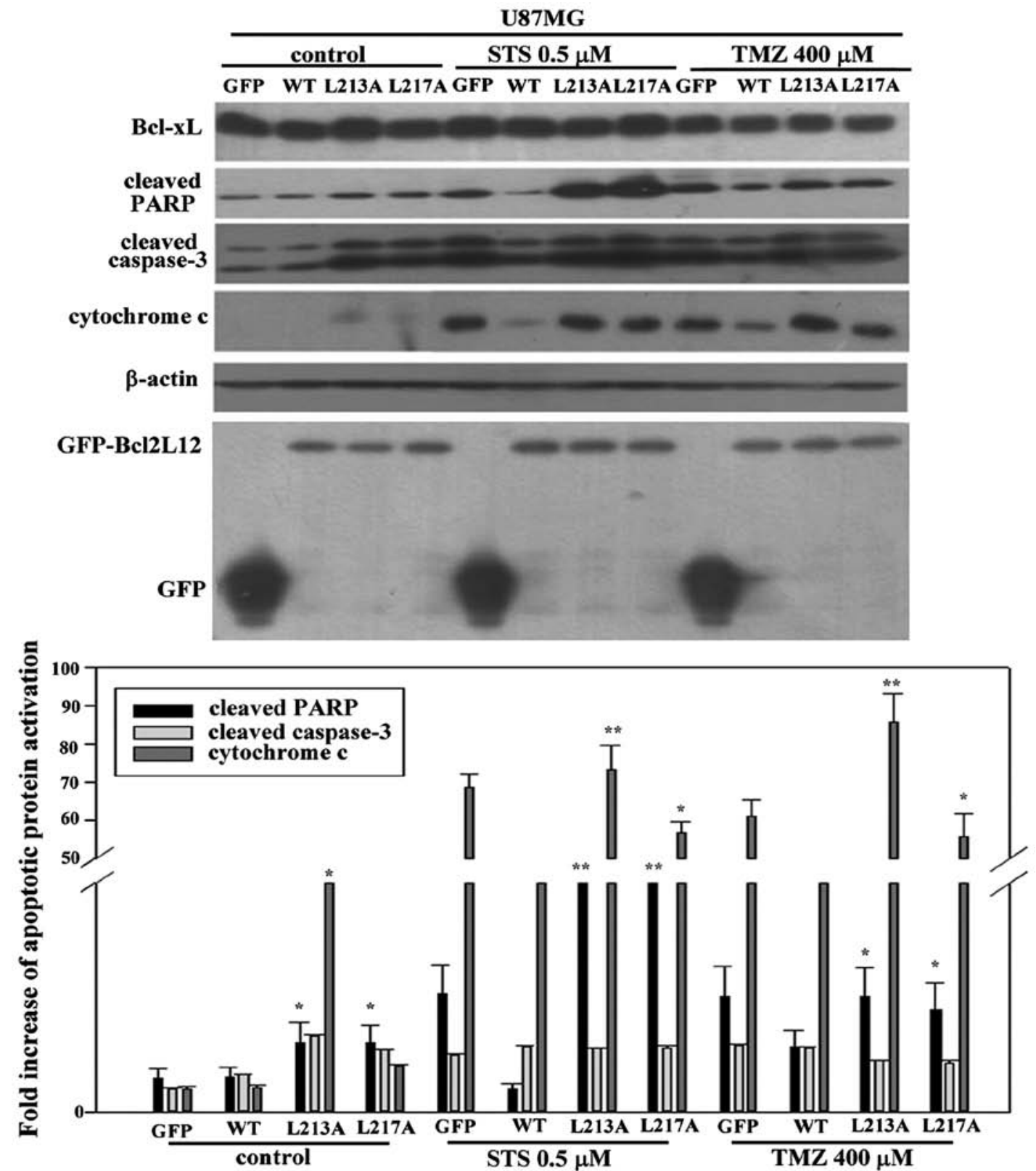

Figure 4. The $\mathrm{h} 1$ and $\mathrm{h} 2$ residue are important in controlling the anti-apoptotic role of Bc12L12. Overexpression of either h1 (L213A) or h2 (L217A) mutant in U87MG cell line disrupted anti-apoptotic role of Bcl2L12 wt, which significantly reactivated expression of cleaved-PARP and induced cytochrome $c$ efflux. The lower panel is the bar chart indicating that expression levels with respect to cleaved-PARP, cleaved caspase-3 and cytochrome $c$ of each gene overexpressing group. The reference values are corresponding expression levels detected in the GFP alone/control group. ${ }^{*} \mathrm{p}<0.05,{ }^{* * *} \mathrm{p}<0.001$.

(Fig. 3). No inter-group difference was found between Bcl2L12 wt and L213 mutant group in expression levels with respect to Bcl-xL, Bax and ratio of Bax/Bcl-xL. To confirm this finding, we further overexpressed another BH3-like mutant domain, h2 mutant (L217A) in U87MG cells of appropriate size. As shown in Fig. 4, without drug treatment, both mutant groups already showed a significantly higher expression of cleaved-PARP compared to Bcl2L12 wt group. However, only h1 mutant showed an evidently higher expression of cytochrome $c$ efflux in untreated control. Using either STS or TMZ caused severe activation of apoptotic markers including cleaved-PARP and cytochrome $c$, but not caspase-3 in GFP alone group. In contrast, overexpressed Bcl2L12 wt prohibited activation of these apoptotic markers. Further, as expectated, overexpression of either h1 or h2 mutant exhibited a reactivation of cleaved-PARP and cytochrome $c$ efflux compared to Bcl2L12 wt group (Fig. 4, lower panel) while Beclin-1 expression in each group seems unaltered.

Combination of TMZ and ABT-737 exerts a superior apoptosis triggering effect in the glioma cell line. For the purpose of evaluating whether Bcl2L12 is promising for target therapy, we introduced ABT-737, a BH3 mimetic agent, to counteract the anti-apoptotic role of Bcl2L12 in glioma since: i) glioma was usually detected with overexpression of Bcl2L12; ii) we speculated Bcl2L12 harbors a functional BH3-like domain, and may play a role similar to that reported for hydrophobic groove of anti-apoptotic members in $\mathrm{Bcl} 2$ family. The results 

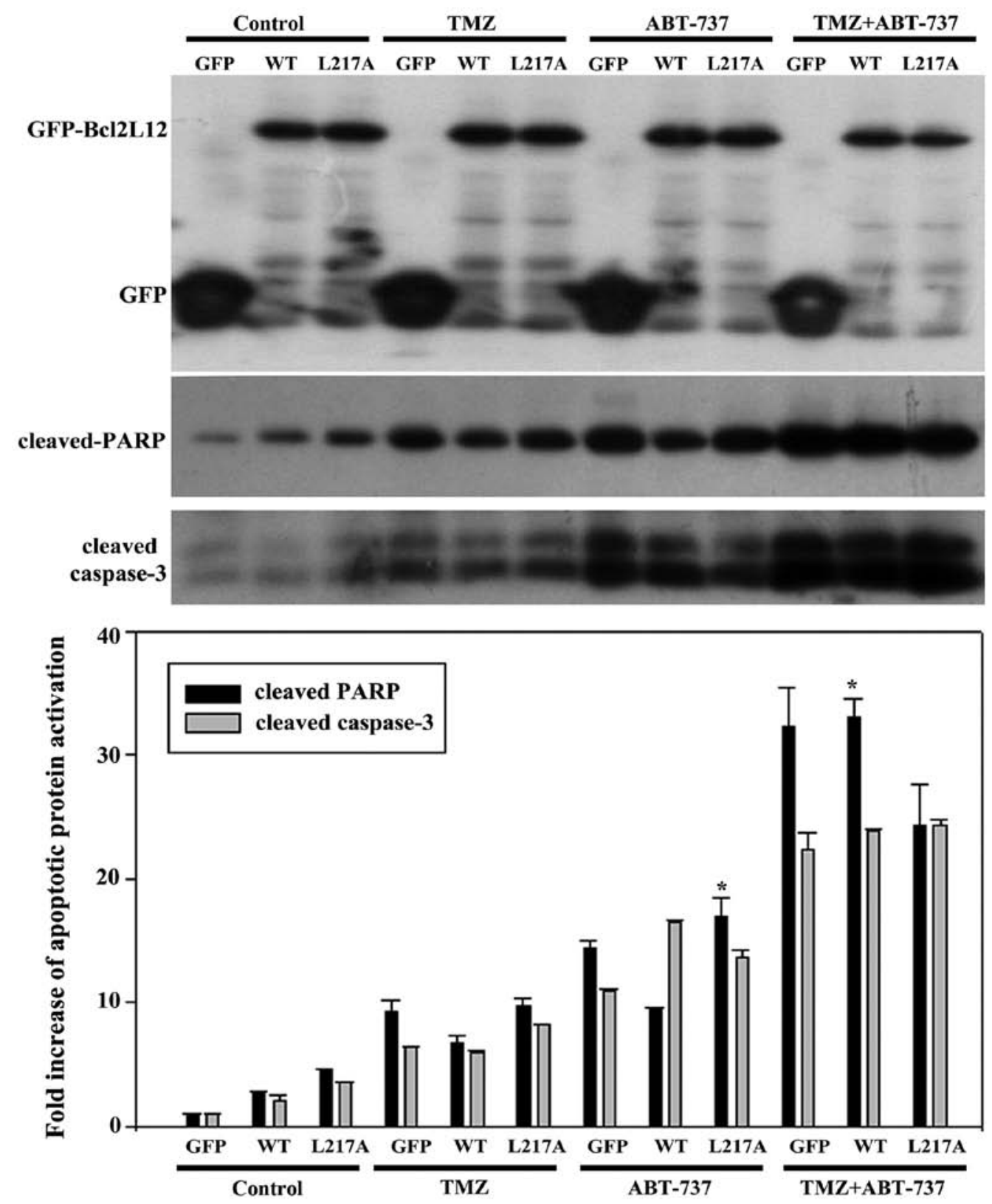

Figure 5. The combination of TMZ and ABT-737 exerts superior apoptosis triggering effect in the glioma cell line. U87MG cells with overexpression of GFP, Bcl2L12wt and L217 mutant were further untreated or treated with TMZ, ABT-737 or both. Cleaved-PARP, cleaved-caspase-3 and GFP-fused Bcl2L12 expressions were detected. The right panel is the bar chart indicating that expression levels with respect to cleaved-PARP and cleaved caspase-3 of each group. The reference values are corresponding expression levels detected in the GFP/control group. ${ }^{*} \mathrm{p}<0.05$.

in Fig. 5, indicate no inter-group difference. Consistently, using either TMZ or ABT-737, overexpressed h2 mutant caused an elevated expression of cleaved-PARP compared to Bcl2L12 wt group. However, using ABT-737 alone, it successfully triggered cleaved caspase-3 expression although it had not reached significant level. The combination with TMZ and ABT-737, it activated approximately 2- and 3-fold enhancement of cleaved-PARP and cleaved caspase- 3 expression, respectively. When compared to single drug treatment, it triggered significantly higher activation of apoptotic markers compared to other Bcl2L12 wt overexpressing groups. These data revealed that mutation on $\mathrm{L} 217$ may partially destroy the linked functionalities of BH3-like domain of Bcl2L12 through a dominant-negative machinery resulting in marginal benefit on re-activation of apoptotic markers when treated with TMZ. Implicating ABT-737 may supply another tool to minimize the functional consequences of BH3-like domain of Bcl2L12 as well as the hydrophobic groove of others anti-apoptotic $\mathrm{Bcl} 2$ members. The combination of TMZ and ABT-737 provide a good microenvironment of ABT-737 and TMZ to take action resulting in the best outcome of triggering apoptosis in the U87MG cell line.

\section{Discussion}

In this study, we demonstrated, for the first time, that Bcl2L12 plays an anti-apoptotic role in a glioma cell line partly due to harboring a $\mathrm{BH} 3$-like domain and through its interaction with 
A

U87

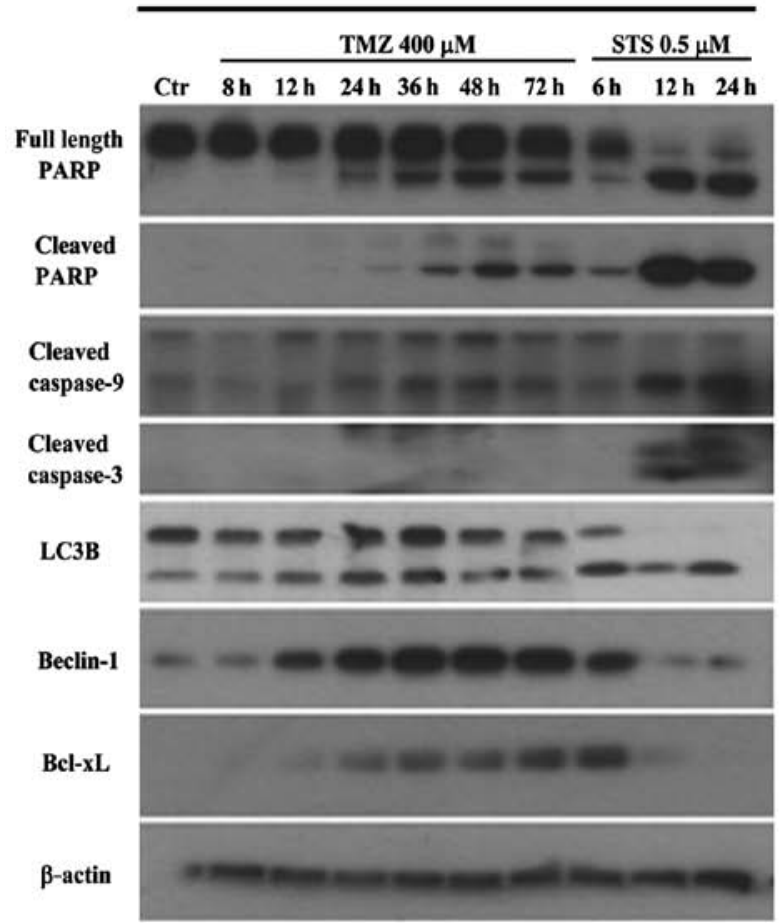

B

Full length
PARP

Cleaved

PARP

Cleaved

caspase-9

Cleaved
caspase-3

LC3B

Beclin-1

Bcl-xL

$\beta$-actin
T98G
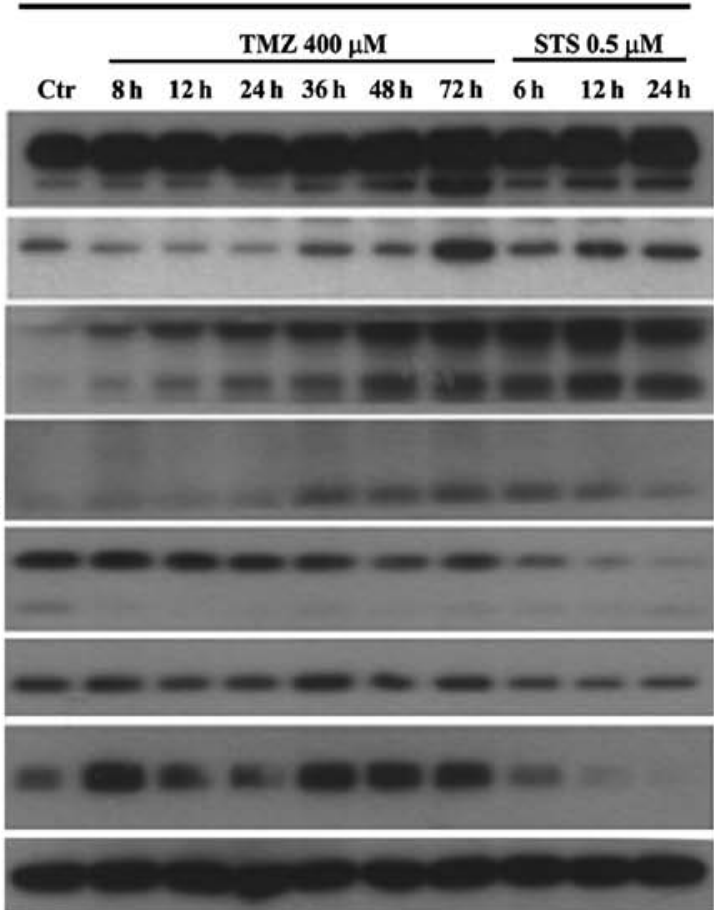

Figure 6. TMZ-induced both apoptosis and autophagy in a time-dependent manner, but with a cell type specificity.

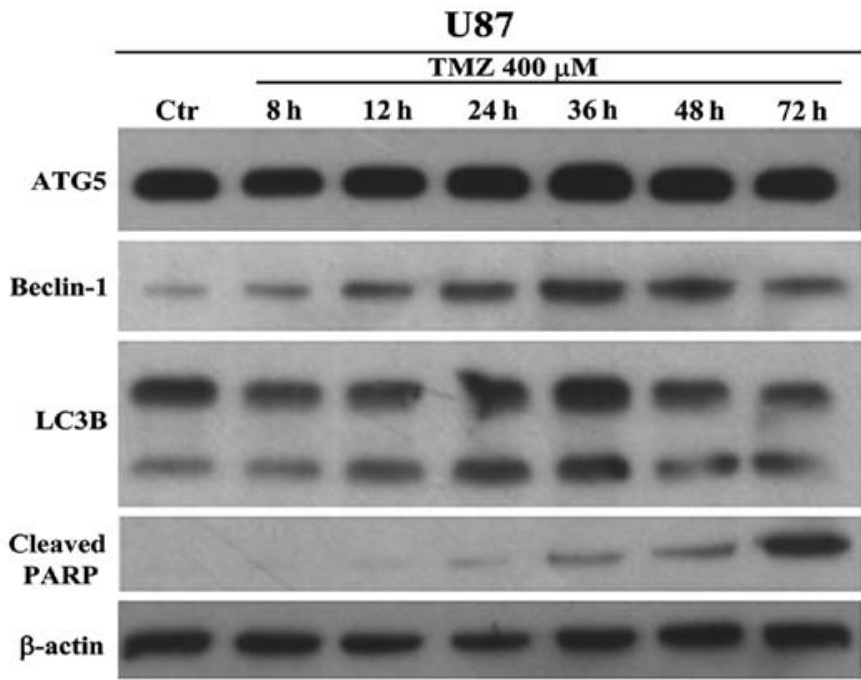

ङ્ّ

TMZ treatment

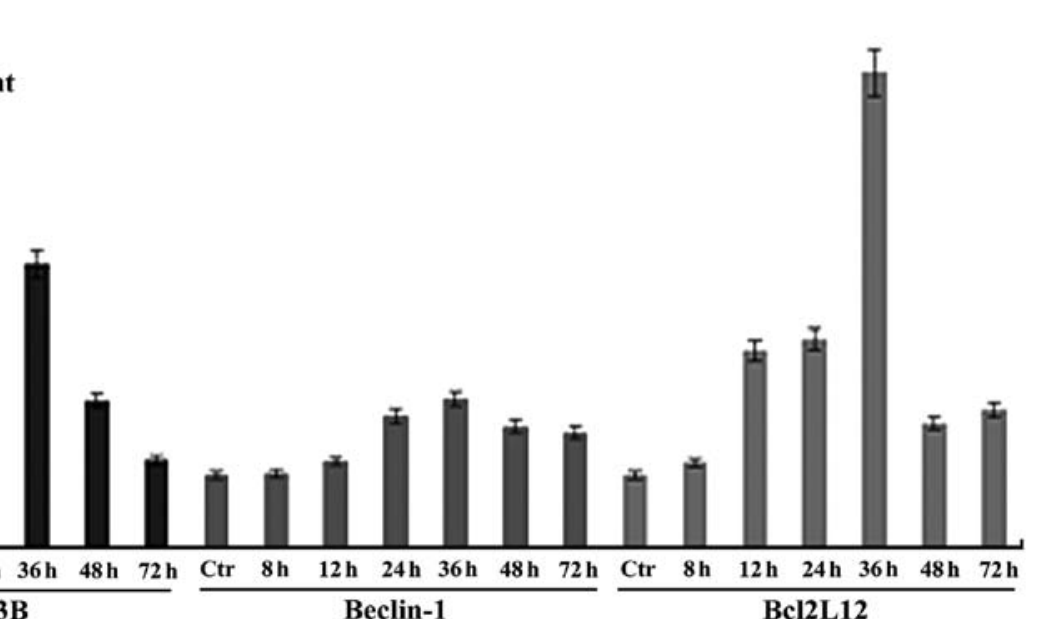

Figure 7. Bc12L12 mRNA expression was induced by TMZ and may play a role in TMZ-induced autophagy in the U87 cell line. 
U87
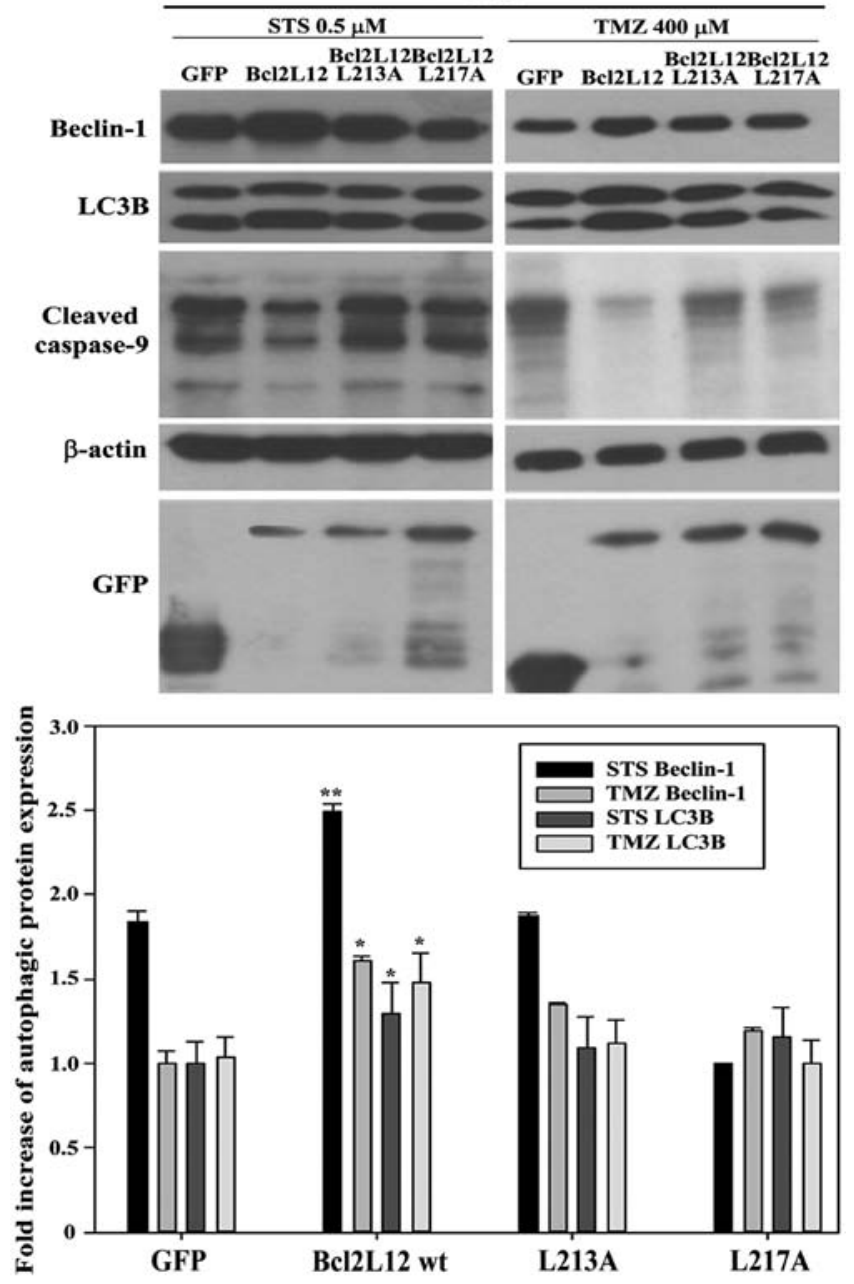

Figure 8. The BH3-like domain of Bcl2L12 may be involved in autophagy and mutation on either $\mathrm{h} 1$ or $\mathrm{h} 2$ residue disrupts this role.

$\mathrm{Bcl}-\mathrm{xL}$ and $\mathrm{Bcl} 2$. This finding is independent of the previously reported mechanisms of p53-dependent or caspase-3/7 inactivation (24,38-40). Mutagenesis on either h1 or h2 residue of BH3-like domain within the hydrophobic groove of Bcl2L12 caused re-activation of apoptotic markers in U87MG cell line with or without treatment with STS or TMZ. These data may provide a new strategy to intervene in those GBM with highly expressing Bcl2L12 through attenuating its BH3-like domain, such as implying the BH3 mimetic agent ABT-737, ABT-263 and analogs corresponding to the Bcl2L12 $211-226$. The possible interaction between Bcl2L12, Bcl-xL and Bcl2 may be important to the anti-apoptotic the role of Bcl2L12; however, this event is unable to deny that p53 may associated with role playing of Bcl2L12 since the reactivation of apoptotic markers of h1 mutant is more evident in U87MG cells (with wild-type p53) than in T98G cells (with p53 codon 237 homozygous mutant) (data not shown). Our finding of h1, h2 and $\mathrm{h} 4$ as important residues in the core motif (position -4 , 0 , and +7) of BH3-like domain of Bcl2L12 may reflect that they serve to interact with Bcl-xL and Bcl2. Interestingly, mutations on corresponding residues of Bax also disrupted the interaction with Bcl2 pro-survival members leading to failure in inducing apoptosis (30).
According to results from the yeast two-hybrid system, full-length Bcl2L12 was unable to interact with Bcl-xL, Bcl2 and Bax until depleting residues 1-70 of its $\mathrm{N}$-terminal. The failure of interaction may be attributed to the Bcl2L12 stereo structural barrier, which similarly to the situation of Bcl2L12 interacts with GSK3 $\beta$ (23). This region of Bcl2L12 $2_{1-70}$ perhaps has some regulatory role on controlling the Bcl2L12 activity and/or interaction. In this study, we did not examine all the interactions between $\mathrm{Bcl} 2 \mathrm{~L} 12, \mathrm{Bcl}-\mathrm{xL}, \mathrm{Bcl} 2$ and $\mathrm{Bax}$ due to problems attributed to secondary generation yeast twohybrid assay. Some of the proteins, such as Bcl-xL and Bcl2, can only be cloned into BD vector and further tested with other proteins. When cloned into the AD vector, the ability of some proteins was reported to be decreased significantly. The problems of directional specific interaction of some proteins should be noted when performing yeast two-hybrid system to avoid both false-negative and -positive results (41). The incomplete evaluation of the interaction between Bcl2L12, $\mathrm{Bcl}-\mathrm{xL}, \mathrm{Bcl} 2$ and $\mathrm{Bax}$ remains as an experimental limitation in this study.

Protein levels with respect to Bcl-xL and Bax did not show a consistent result with apoptotic markers in our western blotting, and these results may be attributed to the mechanism of STS. STS is the broad-spectrum kinase inhibitor that is frequently used as apoptosis inducer in the cell-based assay. However, it may inhibit the phosphorylation on Bcl2 family members to affect the level of these proteins. Moreover, STS induce more abundantly caspase-dependent apoptotic events in the primary cortical neurons (42). This can be part of the reason why the effect attributed to protein-protein interaction of Bcl 2 family proteins is lacking. Therefore, other apoptosis inducer may be used to study variations on the Bcl2 family protein level consequent on overexpressed Bcl2L12 wt and BH3-like domain mutants.

We assumed that, in GBM, the Bcl2L12 is overexpressed and plays an anti-apoptotic role due to, in part, through interacting with Bcl-xL and Bcl2 via a novel BH3-like domain (in this study) to reinforce the integrity of the mitochondria outer membrane. A previous study mentioned that TMZ treatment in GBM may cause autophagy and high ROS production due to ERK1 signaling-mediated autophagy induction (29). We have repeated this phenomenon, and assumed that TMZ-induced both apoptosis and autophagy in a time-dependent manner, but with a cell type specificity as shown in Fig. 6. In U87MG cell line, the elevated expression of Beclin-1 and LC3B was detected at 12 and $24 \mathrm{~h}$, respectively. The expression level of Bcl-xL also gradually accumulated from 12 to $72 \mathrm{~h}$. In contrast, the expression level of cleaved-PARP and cleaved caspase-9 was enhanced until $36 \mathrm{~h}$. The TMZ-induced autophagy to apoptosis shift can be observed in U87MG cell line, but not in T98G when treated with TMZ. To confirm this finding, we perform time-course treatment of TMZ using U87MG cell line, and the TMZ-induced autophagy to apoptosis shift was robustly demonstrated (Fig. 7, upper panel), in which ATG5, Beclin-1 and LC3B all induced expression at early period from 12 to $36 \mathrm{~h}$, but cleaved-PARP was gradually activated beyond $24 \mathrm{~h}$ and highest expressed at $72 \mathrm{~h}$. In addition, we checked mRNA expression pattern with respect to LC3B, Beclin-1 and Bcl2L12 during the trajectory of TMZ treatment showing a consistent rhythm (Fig. 7, lower 
panel), which reached the highest expression at $36 \mathrm{~h}$. These data indicated that Bcl2L12 may be involve in TMZ-induced autophagy. In contrast to previous finding, overexpressed Bcl2L12 wt may cause elevation of Beclin-1 and LC3B, but not cleaved caspase-9 (Fig. 8). Moreover, this phenomenon of autophagic marker induction can be reversed by Bcl2L12 h1 and h2 mutant (Fig. 8), which indicated that BH3-like domain, in addition to apoptosis regulation, was also involved in TMZ-induced autophagy.

In this study, we tested the beneficial outcome for the combination of TMZ and ABT-737. As expected, it provided a superior apoptosis triggering effect than used alone. Moreover, it successfully counteracted that Bcl2L12 wt overexpressing background and produced the best result. Our above data demonstrated that h2 mutant may partially destroy the linked functionalities of $\mathrm{BH} 3$-like domain of Bcl2L12 through a dominant-negative machinery, which probably raised a functional competition with the endogenous Bcl2L12. When treated with ABT-737, the functionality of BH3-like domain of $\mathrm{Bcl} 2 \mathrm{~L} 12$, hydrophobic groove of other $\mathrm{Bcl} 2$ family protein or $\mathrm{BH} 3$ targets may be blocked, and thus an advanced apoptosis inducing effect was observed. The combination of TMZ and ABT-737 provides a good microenvironment to take actions resulting in the best outcome of triggering apoptosis in the U87MG cell line. This phenomenon can be rationalized as follows: i) in U87MG cell line with high Bcl2L12 expression, the TMZ may not work well due to: a) Bcl2L12 helps glioma cells to abrogate the p53-dependent DNA damaging apoptosis event, b) Bcl2L12 is involved in TMZ-induced autophagy and lead to an acquired resistance of TMZ, and c) Bcl2L12 mediates shut-down of caspase-3/-7 activation and upregulated the expression of CRYAB, and thus the caspase-dependent apoptosis might not be easy to launch. However, we found that TMZ can decrease the expression Mcl-1 (data not shown), which alternatively created a good environment for ABT-737 to take action without interfering. The extent of the high Mcl-1 expression would restrict the therapeutic effect of ABT-737 as described (43). Likewise, siRNA-based knock down Mcl-1 expression or implicated pharmaceutical-based (using platinum agent) drug all improved ABT-737 resistance; ii) ABT-737 as BH3 mimetic agent, may be suitable to counteract an anti-apoptotic role of Bcl2L12 in glioma that retains an acquired resistance to TMZ. Abolishing the self-defence of glioma due to Bcl2L12 overexpression, it would be beneficial for TMZ to damage the tumor genome; iii) ABT-737 is broadly antagonists to $\mathrm{BH} 3$ targets through blocking the interaction between anti-apoptotic Bcl2 family proteins and $\mathrm{BH} 3$ provides advantages in triggering more dominant apoptosis. Altogether, the special characteristics of GBM overexpressing Bcl2L12 retain an acquired resistance of TMZ providing ideal conditions for combination use of TMZ and ABT-737. Nonetheless, further insight into the Bcl2L12 multifaceted role in GBM is still needed since it is involved in regulation of apoptosis and autophagy. Eventually, a practical and effective regimen can be developed based on better knowledge of Bcl2L12.

In conclusion, we demonstrated that $\mathrm{Bcl} 2 \mathrm{~L} 12$ has a $\mathrm{BH} 3$-like domain, and it functions similarly to $\mathrm{BH} 3$ domain of $\mathrm{Bcl} 2$ family proteins in binding. Interrupted $\mathrm{Bcl} 2 \mathrm{~L} 12$ interac- tion with $\mathrm{Bcl} 2$ family members can modulate its anti-apoptotic role based on re-activation of apoptotic markers in GBM cell line. The combination TMZ and ABT-737 exerts a better apoptosis induction than each used alone. We conclude that ABT-737 has potential in combination with TMZ to sensitize the drug responsiveness of glioma.

\section{Acknowledgements}

We thank Dr Lynda Chin for providing us with the full length of Bc12L12 plasmid. This study was sponsored by National Science Council-101-2320-B-037-036-MY3, National Science Council-102-2633-B-037-001, National Health Research Intitute-EX100-9809SI (Taiwan), National Sun Yet-San University-Kaohsiung Medical University Joint Research Project-102-P037 and -103-P025 to Yi-Ren Hong, National Science Council-101-2314-B-037-017 (Taiwan) to Shen-Long Howng and 103-CMRPG8C0891 to An-Kuo Chou.

\section{References}

1. Van Meir EG, Hadjipanayis CG, Norden AD, Shu H-K, Wen PY and Olson JJ: Exciting new advances in neuro-oncology: the avenue to a cure for malignant glioma. CA Cancer J Clin 60: 166-193, 2010.

2. Surawicz TS, McCarthy BJ, Kupelian V, Jukich PJ, Bruner JM and Davis FG: Descriptive epidemiology of primary brain and CNS tumors: results from the Central Brain Tumor Registry of the United States, 1990-1994. Neuro Oncol 1: 14-25, 1999.

3. Stupp R, Mason WP, van den Bent MJ, et al: Radiotherapy plus concomitant and adjuvant temozolomide for glioblastoma. N Engl J Med 352: 987-996, 2005.

4. Wang X: The expanding role of mitochondria in apoptosis. Genes Dev 15: 2922-2933, 2001.

5. Ghobrial IM, Witzig TE and Adjei AA: Targeting apoptosis pathways in cancer therapy. CA Cancer J Clin 55: 178-194, 2005.

6. Youle RJ and Strasser A: The BCL-2 protein family: opposing activities that mediate cell death. Nat Rev Mol Cell Biol 9: 47-59, 2008.

7. Yip KW and Reed JC: Bcl-2 family proteins and cancer. Oncogene 27: 6398-6406, 2008.

8. Green DR and Chipuk JE: Apoptosis: stabbed in the BAX. Nature 455: 1047-1049, 2008.

9. Cheng EH, Wei MC, Weiler S, et al: BCL-2, BCL-X(L) sequester $\mathrm{BH} 3$ domain-only molecules preventing BAX- and BAK-mediated mitochondrial apoptosis. Mol Cell 8: 705-711, 2001.

10. Gross A, McDonnell JM and Korsmeyer SJ: BCL-2 family members and the mitochondria in apoptosis. Genes Dev 13: 1899-1911, 1999.

11. Kim H, Rafiuddin-Shah M, Tu H-C, et al: Hierarchical regulation of mitochondrion-dependent apoptosis by BCL-2 subfamilies. Nat Cell Biol 8: 1348-1358, 2006.

12. Wei MC, Lindsten T, Mootha VK, et al: tBID, a membranetargeted death ligand, oligomerizes BAK to release cytochrome $c$. Genes Dev 14: 2060-2071, 2000

13. Wei MC, Zong WX, Cheng EH, et al: Proapoptotic BAX and BAK: a requisite gateway to mitochondrial dysfunction and death. Science 292: 727-730, 2001.

14. Willis SN, Chen L, Dewson G, et al: Proapoptotic Bak is sequestered by Mcl-1 and Bcl-xL, but not Bcl-2, until displaced by BH3-only proteins. Genes Dev 19: 1294-1305, 2005.

15. Walensky LD: Playing fullBAK. Cell Cycle 12: 1333-1334, 2013.

16. Certo M, Del Gaizo Moore V, Nishino M, et al: Mitochondria primed by death signals determine cellular addiction to antiapoptotic BCL-2 family members. Cancer Cell 9: 351-365, 2006.

17. Kuwana T, Bouchier-Hayes L, Chipuk JE, et al: BH3 domains of $\mathrm{BH} 3$-only proteins differentially regulate Bax-mediated mitochondrial membrane permeabilization both directly and indirectly. Mol Cell 17: 525-535, 2005. 
18. Letai A, Bassik MC, Walensky LD, Sorcinelli MD, Weiler S and Korsmeyer SJ: Distinct BH3 domains either sensitize or activate mitochondrial apoptosis, serving as prototype cancer therapeutics. Cancer Cell 2: 183-192, 2002.

19. Kim H, Tu H-C, Ren D, et al: Stepwise activation of BAX and BAK by tBID, BIM, and PUMA initiates mitochondrial apoptosis. Mol Cell 36: 487-499, 2009.

20. Sattler M, Liang H, Nettesheim D, et al: Structure of Bcl-xL-Bak peptide complex: recognition between regulators of apoptosis. Science 275: 983-986, 1997.

21. Walensky LD: BCL-2 in the crosshairs: tipping the balance of life and death. Cell Death Differ 13: 1339-1350, 2006.

22. Scorilas A, Kyriakopoulou L, Yousef GM, Ashworth LK Kwamie A and Diamandis EP: Molecular cloning, physical mapping, and expression analysis of a novel gene, BCL2L12, encoding a proline-rich protein with a highly conserved $\mathrm{BH} 2$ domain of the Bcl-2 family. Genomics 72: 217-221, 2001.

23. Chou C-H, Chou A-K, Lin C-C, et al: GSK3 $\beta$ regulates Bcl2L12 and $\mathrm{Bcl} 2 \mathrm{~L} 12 \mathrm{~A}$ anti-apoptosis signaling in glioblastoma and is inhibited by $\mathrm{LiCl}$. Cell Cycle 11: 532-542, 2012.

24. Stegh AH, Brennan C, Mahoney JA, et al: Glioma oncoprotein Bcl2L12 inhibits the p53 tumor suppressor. Genes Dev 24: 2194-2204, 2010.

25. Hong Y, Yang J, Wu W, et al: Knockdown of BCL2L12 leads to cisplatin resistance in MDA-MB-231 breast cancer cells. Biochim Biophys Acta 1782: 649-657, 2008.

26. Thomadaki H, Talieri M and Scorilas A: Prognostic value of the apoptosis related genes BCL2 and BCL2L12 in breast cancer. Cancer Lett 247: 48-55, 2007.

27. Florou D, Papadopoulos IN and Scorilas A: Molecular analysis and prognostic impact of the novel apoptotic gene BCL2L12 in gastric cancer. Biochem Biophys Res Commun 391: 214-218, 2010.

28. Furnari FB, Fenton T, Bachoo RM, et al: Malignant astrocytic glioma: genetics, biology, and paths to treatment. Genes Dev 21: 2683-2710, 2007

29. Lin CJ, Lee CC, Shih YL, et al: Resveratrol enhances the therapeutic effect of temozolomide against malignant glioma in vitro and in vivo by inhibiting autophagy. Free Radic Biol Med 52: 377-391, 2012.

30. Czabotar PE, Lee EF, Thompson GV, Wardak AZ, Fairlie WD and Colman PM: Mutation to Bax beyond the BH3 domain disrupts interactions with pro-survival proteins and promotes apoptosis. J Biol Chem 286: 7123-7131, 2011.
31. Roy A, Xu D, Poisson J and Zhang Y: A protocol for computerbased protein structure and function prediction. JoVE: e3259, 2011.

32. Yachdav G, Kloppmann E, Kajan L, et al: PredictProtein - an open resource for online prediction of protein structural and functional features. Nucleic Acids Res 42: W337-W343, 2014.

33. Bhat V, Olenick MB, Schuchardt BJ, Mikles DC, McDonald CB and Faroog A: Molecular determinants of the binding specificity of $\mathrm{BH} 3$ ligands to $\mathrm{BclXL}$ apoptotic repressor. Biopolymers 101: 573-582, 2014.

34. Czabotar PE, Westphal D, Dewson G, et al: Bax crystal structures reveal how $\mathrm{BH} 3$ domains activate $\mathrm{Bax}$ and nucleate its oligomerization to induce apoptosis. Cell 152: 519-531, 2013.

35. Wysoczanski P, Mart RJ, Loveridge EJ, et al: NMR solution structure of a photo-switchable apoptosis activating Bak peptide bound to Bcl-xL. J Am Chem Soc 134: 7644-7647, 2012.

36. Petros AM, Medek A, Nettesheim DG, et al: Solution structure of the antiapoptotic protein bcl-2. Proc Natl Acad Sci USA 98: 3012-3017, 2001

37. Suzuki M, Youle RJ and Tjandra N: Structure of Bax: coregulation of dimer formation and intracellular localization. Cell 103: 645-654, 2000 .

38. Stegh AH, Kim H, Bachoo RM, et al: Bcl2L12 inhibits postmitochondrial apoptosis signaling in glioblastoma. Genes Dev 21: 98-111, 2007.

39. Stegh AH, Kesari S, Mahoney JE, et al: Bcl2L12-mediated inhibition of effector caspase-3 and caspase-7 via distinct mechanisms in glioblastoma. Proc Natl Acad Sci USA 105: 10703-10708, 2008.

40. Stegh AH and DePinho RA: Beyond effector caspase inhibition: Bcl2L12 neutralizes p53 signaling in glioblastoma. Cell Cycle 10: 33-38, 2011.

41. Hong YR: False positive: detection and elimination. In: Yeast Hybrid Methods. Zhu L and Hannon G (eds). Eaton publishing, Natick, MA, pp101-113, 2000.

42. Higgins GC, Devenish RJ, Beart PM and Nagley P: Autophagic activity in cortical neurons under acute oxidative stress directly contributes to cell death. Cell Mol Life Sci 68: 3725-3740, 2011.

43. Simonin K, N'Diaye M, Lheureux S, et al: Platinum compounds sensitize ovarian carcinoma cells to ABT-737 by modulation of the Mcl-1/Noxa axis. Apoptosis 18: 492-508, 2013.

44. Oltersdorf T, Elmore SW, Shoemaker AR, et al: An inhibitor of Bcl-2 family proteins induces regression of solid tumours. Nature 435: 677-681, 2005. 